\title{
Human Resource Planning in Education
}

\author{
Gregory W. Ulferts \\ University of Detroit Mercy \\ Evan A. Peterson \\ University of Detroit Mercy \\ Terry L. Howard \\ University of Detroit Mercy
}

\begin{abstract}
Human resource management is about people and organizations, where the significance of group coordination and effective planning strategies work together for achieving success in meeting goals. In the field of higher education, universities and colleges have a crucial role in improving society overall, which is an understanding of moving forward positively through academic achievement and knowledge. By bringing innovative ideas to the forefront of educational attainment, there will be many other opportunities addressed within the framework of HR planning in education. It is a strategic process in many ways, with one of the main issues being an organizational concern. The goals and objectives of schools will need to align effectively with the approaches that HR planning carries out in practice. This essay focuses on the discussion through a unique lens of analysis, including how mission statements and HRM strategies cooperate to improve student performance outcomes.
\end{abstract}

Keywords: human resources, strategy, education, management, planning

\section{INTRODUCTION}

Human resource management is about people and the organizations where groups coordinate effective planning strategies together for purposes of meeting goals. In the field of higher education, universities and colleges have a crucial role in improving society overall, bringing innovative ideas to the forefront of educational attainment, and many other meaningful opportunities addressed in this discussion on human resource planning in education. While different colleges may approach this societal responsibility in their unique manner according to their mission statements, HRM provides a strong foundation for achieving their purposes in the general society as well as in the local communities they serve.

In the case of human resource departments at many colleges and universities around the globe, however, the levels of involvement concerning human resource management planning strategies differ significantly. For example, in a recent research study on colleges in India, the researchers explain that faculty members frequently will need to develop their programs in terms of strategic planning. There are no related HR departments per se, which is often why professors plan various programs in unique, sometimes ineffective ways (Chaturvedi, Chaturvedi, Chaturvedi, \& Rai, 2020). The topic has not been thoroughly researched in 
academic studies to-date. With the increased level of complexity in terms of competitive advantage among various schools, and the need to meet the challenges of increasingly sophisticated, technology-based educational systems, the subject of human resource planning requires greater consideration. In this research study, the focus will be on trends in HRM and strategies for contemporary colleges.

There is a significant level of movement in education to make improvements in human resource planning as the 21 st century evolves. This essay revisits and updates the work of Ulferts, Wirtz, and Peterson (2009) on the college and university use of strategic HRM, a topic of critical importance to the higher education industry due to the havoc caused by COVID-19 and the new standards from the Association to Advance Collegiate Schools of Business (ACCSB). AACSB (2018) accreditation eligibility criteria require that institutions mobilize the resources needed to achieve mission fulfillment. Working successfully towards the mission statement means that college administrators, leaders, and HR managers all will be working together collaboratively at various levels of the business organization. Strategic planning is a critical aspect of these collaborations. Unless HR managers and leaders have a strong focus on the organizational tasks involved with people, there will be disappointments along the way.

By comparison, when strategies align with organizational goals, there will be many opportunities for achieving goals successfully. HR managers may, through the effective use of strategic planning, focus on the critical balance of achieving long-term individual and organizational benefits by having the proper composition of employees positioned in the right place at the right time (Ulferts, Wirtz, \& Peterson, 2009). As a necessary feature of strategic planning for the future, institutions should focus on identifying what they want to achieve in both current planning strategies and long-term planning strategies (depending on the time horizon determined by the school). For example, a school may have a three-year, short-range strategic plan and supplement that plan with a broader set of goals it would like to achieve within a five to ten-year span of time.

Strategic initiatives will explain what the school aims to pursue, and therefore, determine how it will allocate resources for achieving those initiatives on a strategic basis. AACSB (2018) eligibility criteria require that institutions have the continuous support of adequate human, financial, physical, and other infrastructure resources. An institution's strategic plan must include, furthermore, a clearly identified strategy through which the institution will positively affect society, business practice, diversity, and graduate success (AACSB, 2020). The AACSB 2020 Guiding Principles and Standards for Business Accreditation further require that the strategic plan reference policies and procedures for recruiting, retaining, and developing qualified faculty (faculty management model). Institutional strategic initiatives and planning measures, therefore, must address what the school intends to pursue over a period of time, above-and-beyond their regular operational goals. Schools that opt not to include these initiatives in a strategic plan may choose instead to maintain something akin to an operational scorecard. Human resource plans, developed in conjunction with overall strategic plans, afford colleges and universities the opportunity to support their direction in the future through management decisions made in the present (Ulferts, Wirtz, \& Peterson, 2009). It is evident that the significance of focusing on the organizational tasks involved also will depend significantly on a deep understanding of HRM.

\section{DISCUSSION}

In this research study, the primary focus will be about human resource planning in education as it is currently developing in society. Human resource planning is, however, a broad topic that depends significantly on the size of the school, student population, programs offered, and numerous other variables that require specific attention from one region to the next. As noted by AACSB (2018), schools must ensure access to adequate resources necessary to supporting all offered academic programs. Since human resources are all about people at the core level of understanding, it is especially important to recognize the uniqueness of the individual as well as how they fit into the organizational goals overall.

Colleges were places of diversity in sociocultural and academic backgrounds historically, sharing a commitment to achievement in the classroom and future preparedness. Some students, as a result, may be very interested in working together toward the shared goal of the college, while others will mainly be 
focusing on their academic studies and moving as quickly as possible towards graduation. The description of higher education includes postsecondary education colleges and programs, two-year community colleges, four-year colleges, and universities where candidates in various specialized fields of study providing graduate training and baccalaureate degrees (Brint \& Clotfelter, 2016). Within this framework of analysis, these different educational settings differ significantly.

In the 21 st century, there are considerable changes in the ways that colleges - along with the rest of society--are moving forward towards an ever-increasing reliance on technological advancements (Hertel et al., 2013). These changes have increased the level of involvement in schools throughout the culture, which means that there are additional economical and sociocultural factors to consider at nearly every level of the organization. As one example, an academic research study in education noted that the number of postdoctoral fellows, junior faculty, and students who have expressed comfort working with industry signifies a rise in the level of stakeholders connected to academic entrepreneurship (Siegel \& Wright, 2015). The college experience is a highly valued social and economic areas of discussion in modern-day societies around the globe, and success for students means that the future will be better for people on the individual level as well as for the organizations.

Yet there is an increased focus on competition as more schools become successful in bringing promising students to their academic institutions, which places the importance on the perception by the general public of how the various colleges perform. As one researcher explained, concerns relative to how institutions of higher education communicate their impact (on students and communities) and display public value are foremost in the minds of many institutional leaders (Harder, 2019). The significance of HRM planning strategies that provide a more positive view of the schools is, therefore, becoming increasingly more important. Traditional personnel management in colleges and universities are having a difficult time in some cases, where the business models of past generations are not suitable for the current conditions. Strategic human resource management provides a means for colleges and universities to shift away from these outdated business models that are no longer positioned to meet ongoing developmental needs and changes (Dai, 2018).

Conducting an analysis of external labor markets, existing human resources, and expected future operational environments to identify colleges' future needs represents an essential focus of strategic HRM objectives (Ulferts, Wirtz, \& Peterson, 2009). Planning does not mean, however, that the future will be utterly predictable by any means. As the transformations in society and the world are clearly showing in current times, the questions about educational directions are moving along with sociocultural, political, and environmental concerns at a dizzying speed. For example, in the current framework of the global pandemic known as COVID-19, schools from many different regions of the world have been moved entirely to an online platform for several weeks (Editorial Team, 2020). Teachers must have the flexibility needed to respond to these types of unforeseen events with high levels of creative innovation and determine ways to keep students on track academically over time.

Human resource plans must be regularly updated to achieve optimum success and flexibility for organizations (Ulferts, Wirtz, \& Peterson, 2009). Although the factors involved with educational institutions may seem to be more attuned to regular schedules, academic calendars, and many other traditional ways of preparing the next generation of students for their future careers, there have been many rapid developments around the world that show the importance of flexibility; keeping up to date on many different regions of the globe; and similar types of issues (Editorial Team, 2020).

In many ways, these developments may be viewed as part of the educational process itself since the current events are having a significant effect on how students perceive the world. This new normal, as aptly named among journalists, reporters, and the general public, will need to be considered from the perspective of how students and professors respond to the crisis (Editorial Team, 2020). It is an unusual set of circumstances that most likely will change how schools from every region of the globe view the educational process. For example, even though the traditional classroom situation continues to be a place where academic and social concepts are discussed together within the group, these interactions are becoming more widely accepted in the virtual classroom than one might have imagined before the COVID-19 pandemic occurred. 
Remote learning provides opportunities that teachers around the world are learning how to manage as effectively as possible, and many are succeeding (Editorial Team, 2020). A key feature distinguishing human resource administration from operational planning is that analyzing external issues, and considering possible future scenarios, is critical to the success of HR planning strategies (Ulferts, Wirtz, \& Peterson, 2009). Additionally, the importance of classroom interactions that occur on campus may have a crucial role in healing from this crisis on a global scale of perspective. It is challenging to predict, but it provides an interesting discussion for academia that will most likely be prominent in colleges and universities around the world when classes begin to resume.

A college environment is notably a place where a variety of sociocultural factors will have a role in how students engage in academic life. It is a microcosm of society in terms of diversity. These factors will be necessary for human resource management, like any place of employment where those who make decisions on who will fit which particular job description needs to understand the diversity. The differences in values, backgrounds, experience, beliefs, and knowledge from one employee to the next represent a clear indicator as to how human resources differ from other organizational resources (Senyucel, 2009). In educational settings where diversity of experience, knowledge, and culture are the norm, there will still need to be a focus on how to achieve the organizational goals and objectives over time.

The mission goals will differ, and subsequently, the approaches for meeting the current and future needs of the student population also will vary significantly. Yet, there are some developing trends and patterns in contemporary educational settings that may apply to a broad range of situations. Organizational management research studies, as well as research in the social sciences, inform the theoretical basis and the framework in human resource management practices. This research will draw on these resources to highlight current thought on HRM, in addition to studies in educational management. This comprehensive approach provides a unique framework of analysis for developing a balanced perspective on how to make improvements in human resource planning at the college level.

\section{Human Resource Management}

There are many unique ways to approach the topic of human resource management (HRM), but the core level of success focuses on people. From the management perspective, HRM involves "the act of managerial activities and responsibilities concerned with developing and maintaining a competent employee... HRM is concerned with the personnel in an organization and how they contribute to organizational efficiency and effectiveness" (Manzoor et al., 2019, p. 1). This definition does not, however, fully explain why HR managers and leaders are becoming increasingly important in contemporary society. The role of leaders has expanded to include an ability to bring people together in a motivational way-to inspire employees with a feeling of purpose for achieving aspirational goals that matter.

Human resource management is a broad area of research study that has developed some exciting theoretical positions over several decades (Jackson, Schuler, \& Jiang, 2014). It is a growing academic field that continues to evolve through organizational management research studies, some different theoretical perspectives, and a way for organizations to increase the quality of the ways to conduct successful business practices. The term 'strategic HRM,' used broadly by human resource professionals, denotes the common perception that effective HRM is a contributing factor to business effectiveness (Jackson, Schuler, \& Jiang, 2014). By reviewing this analysis, it is evident that HRM is not always viewed in the same way by everyone-far from this concept, the topic of HRM means different things depending on the researcher, the type of business organization studied; the size of the company; goals of the particular market sector; and many related factors that all are developing in a specific way according to current issues in organizational management.

Some researchers, therefore, may focus mainly on organizational tasks required for meeting significant challenges that arise in nearly every business as well as in academia due to the diversity of people in the workplace. Existing research supports the proposition that systems should constitute the primary focus, rather than employees at the individual level, as employees are exposed to interrelated HR practices at any given time (Boon, Hartog, \& Lepak, 2019). A systems approach may be one area of a research study in HRM that provides many benefits for future HR departments as they are developing within the educational 
framework. It may give an organizational method for working effectively in groups, sharing information through advances in technology, and some other advantages for evolving business organizations of the $21 \mathrm{st}$ century.

The systems element of HR systems represents an emerging area of focus within the large body of HRM scholarship (Boon, Hartog, \& Lepak, 2019). For some companies, the complexity of the challenges involved when it pertains to work is considerable and even overwhelming, which means that the leaders may not recognize the value of HR at the individual level. People have unique, individual needs and requirements when it pertains to their working lives, and HR managers must achieve positive relationships with all of their employees.

Thus, the practice of HRM is focused on gaining competitive advantage by creating (and maintaining) a skilled, committed workforce through a mixture of people-centered management practices that treat employees as assets rather than liabilities (Senyucel, 2009). This approach is especially crucial in the education field as the 21 st century progresses. At the level of higher education, HRM planning strategies may need to be engaging and transformational to provide this framework for success.

There are two different views in HRM research studies in business organization and management, where two models exist for separate purposes. In the soft HRM model, the focus will be on employee training and development--nurturing a higher level of commitment among employees which also leads to increased participation in the organizational culture, improved job performance, and a competitive advantage for the company due to these factors (Senyucel, 2009). The Disney model of business organization would be an example, whereby cast members are encouraged to view their participation in work as a lifestyle, receiving perks for their role in the organization, and many other related factors (Salvatico \& Spencer, 2019). Thus, the Disney business model is an example of soft HRM approaches in terms of how employees develop a more personal relationship with their employers supported throughout the business organization.

It is an HRM strategy that provides a high level of cooperation among the various members of the team, and employee performance generally will reflect the training and educational development provided through the company (Senyucel, 2009). This HRM business model focuses on a people-centered approach, as explained through a lens of analysis where employees are valuable assets to the company.

The hard HRM business model has several benefits as well, and by comparing the two different approaches, it is evident that in some market sectors, it may be more valuable for improving a competitive advantage than in others. For example, in a manufacturing business organization, there will be a significant focus on high levels of productivity that do not involve working in customer service. Getting the job done means that those who are unhappy in the company may lose their motivation for one reason or another, and they can easily get replaced-while this attitude may sound harsh, in many manufacturing companies, it is a reality. Strategies where human resource factors are considered relative to business processes to achieve organizational goals, such as achieving cost controls through downsizing, reflects a hard HRM model (Senyucel, 2009.

There are also corresponding theoretical perspectives that accompany each of these HRM models, with not one approach being better than the other. Approaches may differ dramatically based on how the business organization developed over time. Although downsizing in business organizations generally leaves many people without the security of steady employment, the demoralizing effects of this type of situation also may be handled within HRM strategies. Among some methods applied for easing the impact of downsizing recommended by researchers include open learning centers, assessment programs, and career management reviews (Ebadan \& Winstanley, 1997). Cooperative partnerships in business organizations have developed as an increasingly important strategic tool in the 21 st-century organization (Lajara, Lillo, \& Sempere, 2002).

Using Disney as an example once again, the concept of keeping Walt Disney's original plan alive within a large corporation in the world may seem unrealistic. However, it appears to be a positive HRM business model that has promoted an organizational culture focusing on employees as part of a social group as well as those that work for the company in a participatory manner (Salvatico \& Spencer, 2019). 
Since the Disney company has achieved growth productively in many different areas of the business organization over several decades, it is essential to acknowledge that their business model has been flexible over the years. Management has changed several times, and along with these internal changes, the leaders have worked together flexibly on many different business models that reflect changes in society on a global scale (Salvatico \& Spencer, 2019). There are some new developments in HRM strategies in contemporary times. For example, it is becoming increasingly important for employees to develop their initiative in business organizations.

This approach is most frequently discussed as being proactive-where employees at various levels of the company follow through with their unique ideas and ways of approaching customers (Lee, Pak, Kim, $\& \mathrm{Li}, 2019)$. In recent times, the subject of proactivity among successful employees has become an essential topic in HRM academic research. Proactive behaviors, wherein motivated individuals initiate changeoriented action within the organization, are central to fostering innovation (Lee, Pak, Kim, \& Li, 2019, 820). Increasingly, employees are working on their own initiative as organizations are now relatively decentralized (Griffin, Neal, \& Parker, 2007). They have personal knowledge of what is taking place in the field, what customers need, and what inadequacies exist in the system.

Achieving organizational goals in education management has a unique position within the framework of society because there are many different aspects of the educational process to consider a variety of perspectives. In some cultures, there has been a movement in education to develop HRM organization in the schools by learning how business practices and theory has succeeded. For example, the Further and Higher Education Act of 1992 in England stimulated best practices in the commercial sector through emphasizing competition and entrepreneurship (Wolstencroft \& Lloyd, 2019).

The purposes of HRM include many critical factors to consider. Among them, it is crucial for HR leaders to assure that their organization has human resources to meet their goals and operational plansthat is, both current and future needs in terms of qualified people; allowing the organization to be cognizant of social, economic, technological and legal technological trends in terms of human resources, and also being flexible enough to address the dynamic variations in the environment as they are developing (Ulferts, Wirtz, \& Peterson, 2009). In a rapidly changing global society and cultural framework of analysis, these trends have been especially crucial in university settings where students from all over the globe are in attendance at institutions of higher learning. This beneficial factor means that human resources in terms of groups of students, professors, and administration leaders have many opportunities for working together effectively to achieve the goals of particular schools.

From an organizational perspective, effective HRM for those people situated at the more experienced level of management includes the following positive qualities: to establish objectives efficiently; move towards the development and implementation of programs, including finding qualified staff; and providing an appropriate level of training for the new employees and staff members to assure preparation of the people to move forward successfully when needed (Ulferts, Wirtz, \& Peterson, 2009). These organizational procedures are fundamental for achieving success in HR planning strategies in education. With the introduction of the various programs in the school environment throughout the academic schedule, there must be a smooth-running pattern for them to be successful

It is crucial to note, however, that HR departments are not always regulated or well-organized. As one recent research study determined, according to a quantitative analytical focus on the roles of HR managers in over 655 schools in India, significant issues were evident. According to the study findings, it is difficult for individuals to determine the roles and responsibilities assigned to each person, such as roles and responsibilities for coordinating, informing, and performing tasks respectively (Chaturvedi, Chaturvedi, Chaturvedi, \& Rai, 2020). The fundamental issue appeared to be data collection for comparison purposes, which made it more difficult for the researchers to gain a better understanding of where specific challenges.

Data collection is a vital aspect of business organization in schools, which has become increasingly necessary in educational policies and administration. Economic factors are a primary consideration for developing a human resource department, which will need attention during budget planning. In the resource-based view of strategic HRM research, many empirical studies have drawn upon this theory when describing the relationship between HRM systems and organizational performance (Jiang \& Messersmith, 
2018). Another factor that human resource managers will need to develop in the planning stages includes data collection, where the importance of finding staff members that are qualified or especially interested in learning more about technology as it pertains to data analysis will be valuable in the organization (Ulferts, Wirtz, \& Peterson, 2009).

Logistical elements of HR planning in education are also essential for managers to consider during the early phases of an organizational strategy, which includes a year-round program of any type. For example, the group will need to consider and plan for a variety of issues, including the effect that the human resource strategy will have, in terms of equipment, space, funding, supplies, etc., on the organization (Ulferts, Wirtz, \& Peterson, 2009). There are many essential elements to consider as the planning phases of specific programs begin to take shape on the conceptual level of the organization. As another example, accommodations for individuals with disabilities will need to be considered and discussed during the planning stages of any program. In the 21 st century, while solutions may exist for these issues at the administrative level, any type of additional programs or meeting plans that have to do with educational development and training for a position in the HR department will need to be fully explored from this perspective.

Thus, the resources available on college campuses may favor one particular area over anotherespecially if there may be different uses for the auditorium, the student union lounge or conference room, and the like. These issues will need a solution in advance. Although it may seem evident that students will be open to a variety of meeting areas, for example, those who plan HR strategies which include student participation - an approach that makes more sense than any other arrangement, if one considers the high level of value for the HR department and for the students together in a collaborative partnership for meeting shared goals and mission of the school overall-there still will need to be on campus regulations to consider as well as a conflict of interest. These logistical situations highlight the importance of organization and planning, which forms the basis of achieving success at the core levels of the overall goals and objectives of the school.

\section{Modeling and Forecasting}

There are some specific phases to consider within the structure of strategic HR planning. For example, the uses of modeling and forecasting together may provide the HR management team with tools for learning critical information on the topic of how various HR strategies may be used effectively-primarily as a supportive way for moving forward in achieving the goals of the business organization (Ulferts, Wirtz, \& Peterson, 2009). Modeling and forecasting methods used in strategic HRM planning in education may range from simple types of techniques to plans of graduating levels of complexity.

One of the most critical considerations for purposes of developing an effective HR strategy is for planners to use straightforward, easily understood methods - as researchers in HRM have learned, the direct approach improves results because it is more likely that the group will accept the results among team members of the group (Ulferts, Wirtz, \& Peterson, 2009). The first step will be to engage in a forecast of HR projections well in advance. Some of the most critical questions in the forecasting stages may include the following: "How many faculty members or staff members are necessary to achieve the college's strategic goals? What roles and responsibilities need to be covered? What skillsets and credentials will individuals need to perform these roles and responsivities (Ulferts, Wirtz, \& Peterson, 2009)? This process of data collection and analysis may be conducted in the spring or earlier to plan for an organized way to fit the information into budgetary discussions for the fall, a time when most schools traditionally begin the academic year. This aspect of HR planning in education is flexible and most often discussed at the administrative level of business organization.

For some colleges, it may not even be unusual to send out this type of information over a year in advance. Policies in the HR department will vary considerably, which is an expected and necessary aspect for planning effective HR strategies that fit suitable within the school's organizational culture. In any case, the processes involved with preparing a well-developed forecast are complex. They will need to be worked out by personnel or faculty with a high level of academic knowledge in different types of quantitative analysis, including demand forecasting techniques (regression analysis, time series analysis, simple 
percentage changes) and integrated models (linear programming, goal programming, network models) (Ulferts, Wirtz, \& Peterson, 2009).

In strategic HR management and planning research studies, the importance of working collaboratively as a business-unit people plan has been compared to the idea of competitive strategy as it pertains to business planning (Kesler, 2000). This approach means that personnel in the HR department will write up a document that explains how the plan fits HR strategies-how they will develop, what the main points of the development are, and other important concepts that inform the particular approach in mind.

The business-unit people plan also may be explained as a human resources plan. Key assumptions, resulting strategies, clearly defined roles and responsibilities, and implementation timelines, represent just some of the essential points to be included in this brief human resource document (Ulferts, Wirtz, \& Peterson, 2009). This explanation provides a guideline for the upcoming plans and procedures in an efficient, organized manner. There should be very little left up to chance. However, it is important to acknowledge from the outset that in contemporary times leaders with a higher level of flexibility and resilience to change are at a competitive advantage in many organizations.

\section{Data Collection}

Data collection is a vital aspect of business organization in schools, which has become increasingly necessary in educational policies and administration. Economic factors are a primary consideration for developing a human resource department, which will need attention during budget planning. Another factor that human resource managers will need to develop in the planning stages includes data collection, where the importance of finding staff members that are qualified or especially interested in learning more about technology as it pertains to data analysis will achieve value in the organization (Ulferts, Wirtz, \& Peterson, 2009). Logistical elements of HR planning in education are also essential for managers to consider during the early phases of an organizational strategy, which includes a year-round program of any type. As noted above, the group must consider and plan for a variety of issues in terms of equipment, space, funding, supplies, etc. (Ulferts, Wirtz, \& Peterson, 2009). For example, the group will need to organize and plan for various issues, among them, "the implications for space, equipment, and other existing resources that the human resource plan will have upon the organization... has sufficient office space, supplies, and funds to accommodate the additional employees" (Ulferts, Wirtz, \& Peterson, 2009, p. 7). There are many essential elements to consider as the planning phases of specific programs begin to take shape on the conceptual level of the organization.

\section{Logistical Elements of HR Planning in Education}

Accommodations for individuals with disabilities will need to be considered and discussed during the planning stages of any program. In the 21st century, while these issues may have a solution at the administrative level, any type of additional programs or meeting plans that have to do with educational development and training for a position in the HR department will need to be fully explored from this perspective. Thus, the resources available on college campuses may favor one particular area over another-especially if there may be different uses for the auditorium, the student union lounge or conference room, and the like. These issues will need a solution in advance.

Although it may seem evident that students will be open to a variety of meeting areas, for example, those who plan HR strategies which include student participation - an approach that makes more sense than any other arrangement, if one considers the high level of value for the HR department and for the students together in a collaborative partnership for meeting shared goals and mission of the school overall-there still will need to be on campus regulations to consider as well as a conflict of interest. These logistical situations highlight the importance of organization and planning, which forms the basis of achieving success at the core levels of the overall goals and objectives of the school.

One way to achieve these characteristics is for people who are working in strategic HR management to study many different aspects of the educational environment. Planning processes, both medium-term planning and long-term planning, reflect accumulated experience relative to preliminary efforts and an allinclusive analysis of a college or university's future internal and external environment (Chen, 2017). These 
essential objectives are widely available in contemporary times, which refers to the relative accessibility for doing ample research about the background information on schools. In present times, transparency is an essential way for companies to achieve optimum success within the general public view.

Evaluative measures for understanding the directional trends in society are essential for planning strategic HR management approaches. Effectiveness in the 21st century means that increased knowledge about every aspect of a company provides a competitive advantage, where the solutions for finding ways to go are attainable as long as people maintain a focus on their goals. It may appear like a simple process, but it requires extensive research on background information that is relevant for planning for the future (Chen, 2017).

\section{CONCLUSION}

Human resource management is about people and the organizations where groups coordinate effective planning strategies together for purposes of meeting goals. In the field of higher education, universities and colleges have a crucial role in improving society overall, bringing innovative ideas to the forefront of educational attainment, and many other significant opportunities addressed in this discussion on human resource planning in education. While different colleges each may approach this societal responsibility in their unique manner according to their particular mission statement, HRM provides a strong foundation for achieving their purposes in the general society as well as in the local communities they serve. However, in cases of human resource departments at many colleges and universities around the globe, the levels of involvement where human resource management planning strategies are concerned to differ significantly.

Moving forward in the direction of human resource planning in education as the 21 st century progresses, HR managers and leaders need to implement organizational procedures that are suitable for the many challenges ahead. These processes have a crucial role in developing effective HR strategies that are effective in terms of organizational performance, achievement, and success. This explanation means that the school's objectives outlined in the mission statement and vision of educational leaders will align effectively with HR management strategies in education.

Preparedness is critical for success overall, which means that the HR managers, faculty members, staff, and students all will need information throughout the school year and beyond. These evaluative measures have a vital position in developing plans for the future; improved planning strategies which align with the students both now and in the future. It is an organizational process that points in the right direction, rather than in less predictable ways. The selection of benchmarks, and their measurement over time, is necessary for determining whether the plan is achieving the desired objectives. This approach provides many benefits for the organization, particularly in terms of bringing innovative ideas to the forefront of educational attainment; and many other valuable opportunities highlighted in this discussion on human resource planning in education. As discussed throughout this research essay, it is essential to acknowledge that different colleges each may approach this societal responsibility in their unique manner according to their particular mission statement, HRM provides a strong foundation for achieving their purposes in the general society as well as in the local communities they serve.

\section{ACKNOWLEDGEMENT}

This public-interest article contains duplicative, historical information and updates the original work of Ulferts, G., Wirtz, P., \& Peterson, E. (2009). Strategic human resource planning in academia. American Journal of Business Education (AJBE), 2(7), 1-10. https://doi.org/10.19030/ajbe.v2i7.4123. 


\section{REFERENCES}

Association to Advance Collegiate Schools of Business. (2018). 2013 eligibility procedures and accreditation standards for business accreditation. Retrieved from https://www.aacsb.edu//media/aacsb/docs/accreditation/business/standards-and-tables/2018-businessstandards.ashx?la=en\&hash=B9AF18F3FA0DF19B352B605CBCE17959E32445D9

Association to Advance Collegiate Schools of Business. (2020). Guiding principles and standards for business accreditation. Retrieved from https://www.aacsb.edu/-

/media/aacsb/docs/accreditation/business/standards-andtables/ed22020\%20aacsb\%20business $\% 20$ accreditation $\% 20$ standards $\% 20 \% 20$ final $\% 20 \% 20 \mathrm{pdf} \%$ 20for\%20release $\% 20 \% 2002032020$.ashx?la=en\&hash=62E26CF8B3D1836BE46BB08F51C1A D57A748E54E

Boon, C., Den Hartog, D.N., \& Lepak, D.P. (2019). A systematic review of human resource management systems and their measurement. Journal of Management, 45(6), 2498-2537. Retrieved from https://journals.sagepub.com/doi/pdf/10.1177/0149206318818718

Brint, S., \& Clotfelter, C.T. (2016). US higher education effectiveness. RSF: The Russell Sage Foundation Journal of the Social Sciences, 2(1), 2-37. Retrieved from https://muse.jhu.edu/article/612990/pdf

Chaturvedi, J., Chaturvedi, A., Chaturvedi, R., \& Rai, M. (2020). Role of human resource management and quality management in higher educational institutions theme: Innovative functional strategies for Gen Y. Studies in Indian Place Names, 40(3), 1461-1490. ISSN: 2394-3114

Chen, Y. (2017, May). A study on strategic management of higher vocational colleges. In 2017 th International Conference on Education, Management and Computing Technology (ICEMCT 2017). Atlantis Press. Retrieved from file:///C:/Users/newuser/Downloads/25874347.pdf

Dai, X. (2018, November). Evolution of personnel management in colleges and universities to strategic human resources management and ways to realization. In 2018 th International Conference on Education, Management, Arts, Economics and Social Science (ICEMAESS 2018). Atlantis Press. Retrieved from file:///C:/Users/newuser/Downloads/25906245.pdf

Ebadan, G., \& Winstanley, D. (1997). Downsizing, delayering and careers--The survivor's perspective. Human Resource Management Journal, 7(1), 79-91. Retrieved from https://onlinelibrary.wiley.com/toc/17488583/1997/7/1

Editorial Team. (2020, April 2). A teacher's guide to remote learning during COVID-19. Retrieved from https://blog.westerndigital.com/teachers-guide-remote-learning-covid-19/

Harder, W. (2019). Analyzing public relations as a strategic management function at SEC universities MPA/MPP Capstone Projects, 317, 1-50. Retrieved from https://uknowledge.uky.edu/mpampp_etds/317

Hertel, G., van der Heijden, B.I., de Lange, A.H., \& Deller, J. (2013). Facilitating age diversity in organizations-part I: challenging popular misbeliefs. Journal of Managerial Psychology. DOI 10.1108/JMP-07-2013-0233

Jackson, S.E., Schuler, R.S., \& Jiang, K. (2014). An aspirational framework for strategic human resource management. The Academy of Management Annals, 8(1), 1-56. DOI: $10.1080 / 19416520.2014 .872335$

Jiang, K., \& Messersmith, J. (2018). On the shoulders of giants: A metareview of strategic human resource management. The International Journal of Human Resource Management, 29(1), 6-33. DOI: $10.1080 / 09585192.2017 .1384930$

Kesler, G. (2000). Four steps to building an HR agenda for growth: HR strategy revisited. People and Strategy, 23(3), 24-32. Retrieved from https://www.questia.com/library/journal/1G169279717/four-steps-to-building-an-hr-agenda-for-growth-hr

Lajara, B.M., Lillo, F.G., \& Sempere, V.S. (2002). The role of human resource management in the cooperative strategy process. Human Resource Planning, 25(2), 34-44. Retrieved from https://www.jstor.org/stable/41472064?seq=1 
Lee, H.W., Pak, J., Kim, S., \& Li, L.Z. (2019). Effects of human resource management systems on employee proactivity and group innovation. Journal of Management, 45(2), 819-846. DOI: $10.1177 / 0149206316680029$

Manzoor, F., Wei, L., Bányai, T., Nurunnabi, M., \& Subhan, Q.A. (2019). An examination of sustainable HRM practices on job performance: An application of training as a moderator. Sustainability, 11(8), 1-19. DOI:10.3390/su11082263

Salvatico, Y.M., \& Spencer, F.W., IV. (2019). Disney's workforce of the future: From HR initiative to organizational culture. In Futures Thinking and Organizational Policy (pp. 347-375). Palgrave Macmillan, Cham. Retrieved from https://link.springer.com/chapter/10.1007/978-3-319-94923$9 \_17$

Senyucel, Z. (2009). Managing the human resource in the 21st century. BookBoon: London, UK. Retrieved from http://thuvienso.bvu.edu.vn/bitstream/TVDHBRVT/15789/1/Managing-theHuman-Resource.pdf

Siegel, D.S., \& Wright, M. (2015). Academic entrepreneurship: time for a rethink? British Journal of Management, 26(4), 1-39. Retrieved from https://onlinelibrary.wiley.com/doi/10.1111/14678551.12116

Ulferts, G., Wirtz, P., \& Peterson, E. (2009). Strategic human resource planning in academia. American Journal of Business Education (AJBE), 2(7), 1-10. https://doi.org/10.19030/ajbe.v2i7.4123

Wolstencroft, P., \& Lloyd, C. (2019). Process to practice: The evolving role of the academic middle manager in English further education colleges. Management in Education, 33(3), 118-125. DOI: $10.1177 / 0892020619840074$ 